\title{
Training of "Set" Thinking Mode in Traditional Theory Composition Teaching
}

\author{
Weixin Ren \\ Sichuan Normal University \\ Chengdu, China
}

\begin{abstract}
The most important thing in music creation is the cultivation of thinking mode and personal consciousness, that is, how to use rational techniques to properly express the perceptual "motives". The author believes that the accumulation of these emotional "motives" should be slightly quantized. In this paper, the author calls this mode of thinking "set" mode of thinking. This paper attempts to take different music works as examples, from three aspects, from the whole to the part, to explore the methods for training of "set" thinking mode in traditional theoretical composition teaching. In the first part, the author puts forward to train it from the analysis of musical works; in the second part, proposes to train it from the composing process; and in the third part, suggests training it from the sight singing and ear training course. The discussion process of the three parts is all combined with spectral examples and illustrations.
\end{abstract}

Keywords-traditional theoretical composition; mode of thinking; arrangement; sight singing and ear training; work analysis; twelve-tone system; scale set

\section{INTRODUCTION}

Since the development of traditional theoretical composing discipline, systematic composing techniques and diversified composing methods have already been formed. The composing circle has shown a great contention among hundreds of schools of thought. Composers have unique thinking modes when creating their own works, and guide their students to use different thinking modes to create works. Schoenberg's Fundamental Principles of Composition, finished from 1937 to 1948, Hendermitt's Three Volumes of Composition Techniques, Messian's My Musical Language Techniques and Zhao Xiaosheng's Traditional Composition Techniques all guide students to organize music, express their feelings and engage in creative activities of composition from different perspectives. Some of them are from the form structure, some from the pitch structure, some from the "style" and writing methods to guide students to compose. However, in the actual teaching process, the author finds that the problems that students encounter are often not manifested in some obvious aspects. For example, Zhao Xiaosheng mentioned in his book Traditional Composition Techniques that "through imitation accumulate basic ability in composition and through free writing stimulate originality", and put this concept in the process of practice. Students often find it difficult to produce qualitative change on the basis of imitation, so most of the works created have original "shadow", and it is difficult to get out of their own way. In my opinion, the most important thing in music creation is the cultivation of thinking mode and personal consciousness, that is, how to express emotional "motive" properly with rational techniques. The author believes that the accumulation of these emotional "motives" should be slightly quantized. Different works may have same or similar sound organization. Composers produced different emotional colors in different contexts and different experiences. Although these short "motives" are abstract and fleeting, but if you constantly accumulate "motives" you want to express, you will get the desired sound effect in the process of composition. In this paper the author called it the "set" mode of thinking. The common meaning of "set" refers to the combination group with a certain number of sounds. It refers to the sound organization form after the combination of the sounds in the works through a series of changes in pitch positions and time sequence. The reason why this mode of thinking is called "set" mode of thinking in this paper is that the core motivation material that composers want to express can be called "set" either in the period of "general writing" or in the period of free atonal writing. In the specific teaching practice, if we consciously cultivate this mode of thinking, students will be more likely to express the emotional content they want to express and have their own style in the process of music creation. So, what aspects do we need to start with in order to cultivate such a way of thinking? The author discusses it from three aspects.

\section{TO TRAIN IT FROM THE ANALYSIS OF MUSICAL WORKS}

The analysis of music works in different periods helps students understand the core motives that composers in different periods wanted to express in their works. These motives, like some of the most important vocabularies, were integrated into the overall structure of the composer. Mr. Chen Hongduo once mentioned the word "deconstruction" in his interpretation of Ligeti's works. Then, the most important point of deconstruction is to let students understand the sound effect that the composer wanted to express. Most of the sound effects will resonate with "motivation" of students' creation, so as to guide students to create works with similar materials but different sound effects. 


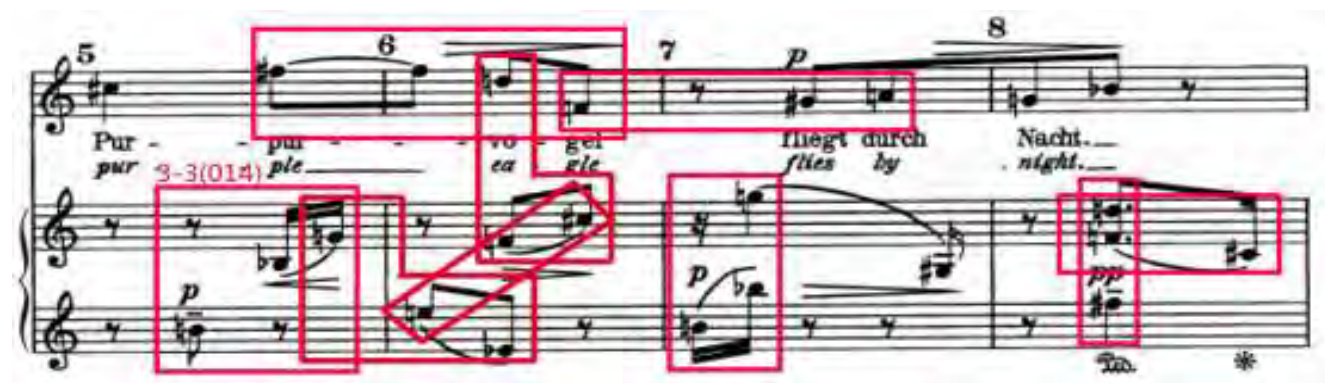

Fig. 1. Score 1: Webern's Three Artistic Songs No. 2 (5 8 bars).

This is a free atonal work of Anton Webern. Through the sequence analysis of the whole work with "the twelve-tone matrix", it can be seen that the composer has only adopted four different forms of sequence, namely P0, I0, R0 and RI0. (See "Fig. 1") However, the four sequence forms are skillfully and purposefully combined with the vocal part and accompaniment after the composer uses many sequence techniques such as "sequence overlap method", "vertical and horizontal method" and "segmentation method". The purpose of this combination is to highlight the sound effect of the core motive 3-3 (014) (101100) that the composer wants to express. The composer has emphasized the sound effect 63 times in the whole song. So after analyzing this work, the teacher should let the students accumulate such sound effects at different pitches and complete similar composition. Such composition is not only a simple imitation, but also let the students explain their creative thinking in the process of completion of the work, the similarities and differences between the sound effects they want to achieve and the original work, so as to accumulate different "set" of feeling. And use the "set" thinking mode to classify them, that is, under what kind of emotions the use of such voice organization will be more reasonable, and the answer is definitely different. After guiding students to sum up, individual differences will emerge, resulting in different individuals producing different styles of works and accumulating different emotions that they want to express by the same core pitch material.

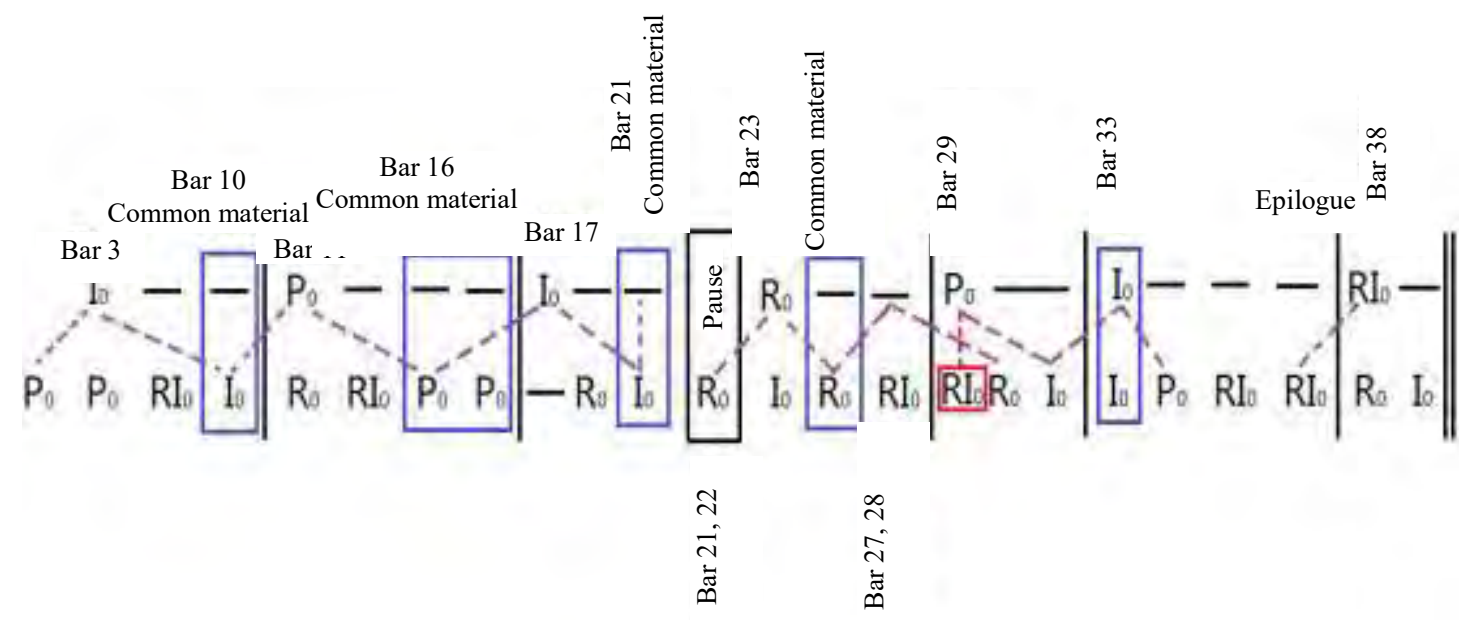

Fig. 2. Sequence diagram of the whole work.

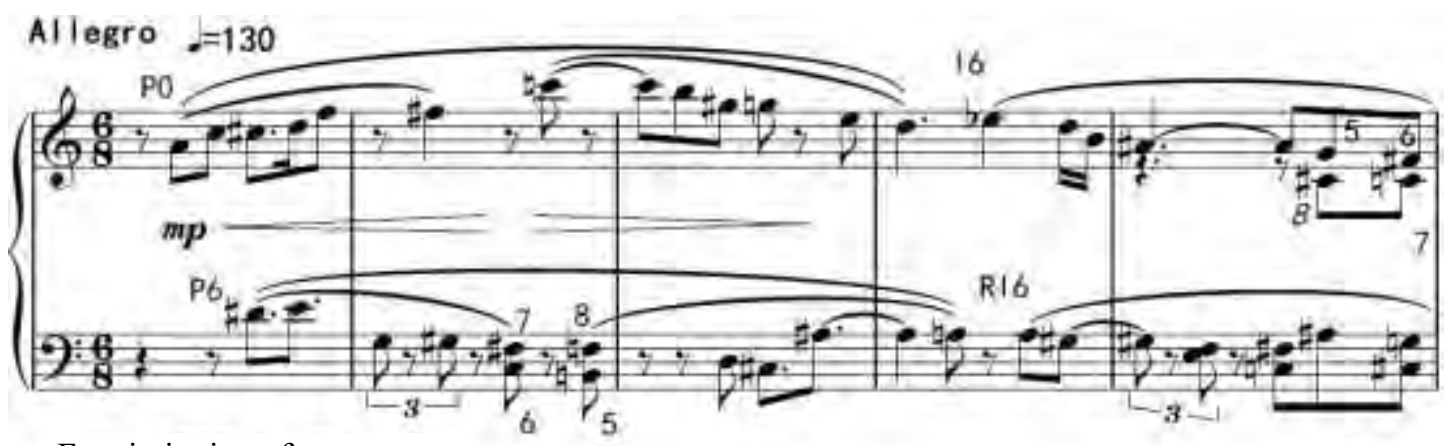

Free imitation of two parts

Fig. 3. Score 2: Exercises of a student (1 5 bars). 
This example is an exercise of a student. Through the analysis of Webern's Three Songs NO.2, we can understand the core pitch material that the composer wanted to express, and create a piano work motivated by the core pitch material. It is interesting that different students create different sound effects with the same core pitch material in such exercises. Such exercises with the same material do not appear only once, aiming at producing different effects from students' different creative states. Such exercises can stimulate students' creative possibilities to the greatest extent. Taking this student's work as an example, he made a symmetrical choice of six-tone scales and elaborated his idea, what kind of mood he wanted to express, and what difference was the effect of his work from Webern's. The following picture shows the sequence that students chose to use in his composition.

Symmetrical sequence, Hexachord

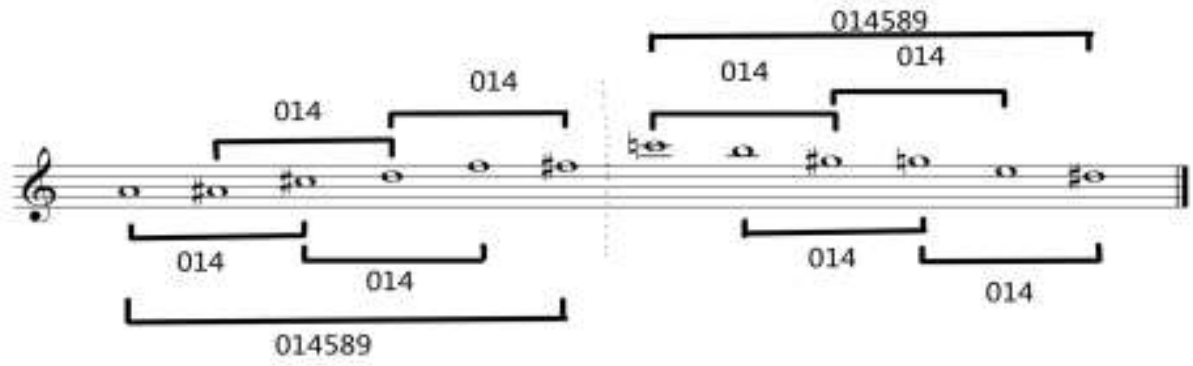

Fig. 4. Symmetrical sequence, Hexachord.

This sequence is a special symmetric shift sequence. From the point of view of the set, it can completely map itself in the shift just like the diatonic scale. This sequence derives from the symmetric shift set from 6-20 (014589). Because shift symmetry is a very rare property, only twelve sets have such properties, including 3-12, 4-9, 4-25, 4-28, 6-7, 6-30, 6-20, 6$35,9-12,8-9,8-25$ and 8-28 in "Fig. 4". After describing the selected core pitch materials, the students made a contrastive explanation according to the original works.

From the above two examples in "Fig. 2" and "Fig. 3", it is easy to see that the training of "set" thinking mode can enable students to compare and think divergently in the process of imitation. The experience of a composer is different from that of a student, so even works created with the same material will be different. If there is no "set" way of thinking, just stay in simple imitation, melodic imitation, pitch structure and music structure, and the composing process would be dull without students' own feelings. Therefore, the author believes that most teachers should realize that the works created by many students are too "mechanized" because they do not bring in their own feelings or even do not know what they are writing. Let alone create life and spirit in their works, and naturally will not arouse the resonance of the audience. For example, in a simple tri-syllable group, different pitch orientation or in different range can cause different feelings of the audience, let alone a core motivation. Therefore, the "set" mode of thinking can be regarded as a quantified way of thinking on the selection of the core motivation, as well as a way of creative practice in self-summarizing and forming one's own style.

\section{TO TRAIN IT FROM THE PROCESS OF COMPOSITION}

Since the development of traditional theoretical composition, composers have notated music on handwritten paper, and later some composers select to use Sibelius or Finale. Whichever way of recording music, composers need to have good inner hearing. They can first reflect the sound effect of the music in their hearts and modify it. Although the music playing software will have its own sound effect, but often it is not so close to the real instrument's timbre, and the difference of timbre will lead to incomplete predication on expression of the emotional content and errors in use of composing techniques. And the sound effect when recorded on the scene is quite different from the effect of their inner presentiment. The composer Mr. Liu Wei once said, "I think only what the composer expresses is the hottest thing", but often our students do not have such good inner hearing, and it is normal for them to make mistakes. The "set" mode of thinking is to create one's own works by analyzing the core pitch material of each work. In the process of composition, the author thinks that we can use the advanced compilation software to make a direct comparison of the sound effects, which will help students feel the construct of different instruments more intuitively, and make the pitch combination and express their thoughts more accurately. Take the core pitch motivation 3-3 (014) (101100) of No. 2 in Webern's Three Songs as an example. Use 
instruments with different timbre to play different pitch positions, and the effects will vary greatly. Taking pipa as an example, if national orchestral works are composed, there will be many kinds of timbres of pipa, even involving the ancient silk-road instrument Southern Pipa. Therefore, to cultivate the "set" mode of thinking from the process of composing will enable students to more intuitively feel the actual sound effect, and accumulate more special core motivation of the sound effect. Much arrangement software has a high degree of restoring the original timbre of all kinds of instruments, such as Logic and Cubase. The software has a very clear Sound Library. If you need more refinement, you can download the sound source software Kontakt to screen all kinds of instruments, and more accurately feel the difference of the timbres of various instruments, so that you can choose the most desired type for composition. Kontakt interface is shown in "Fig. 5".

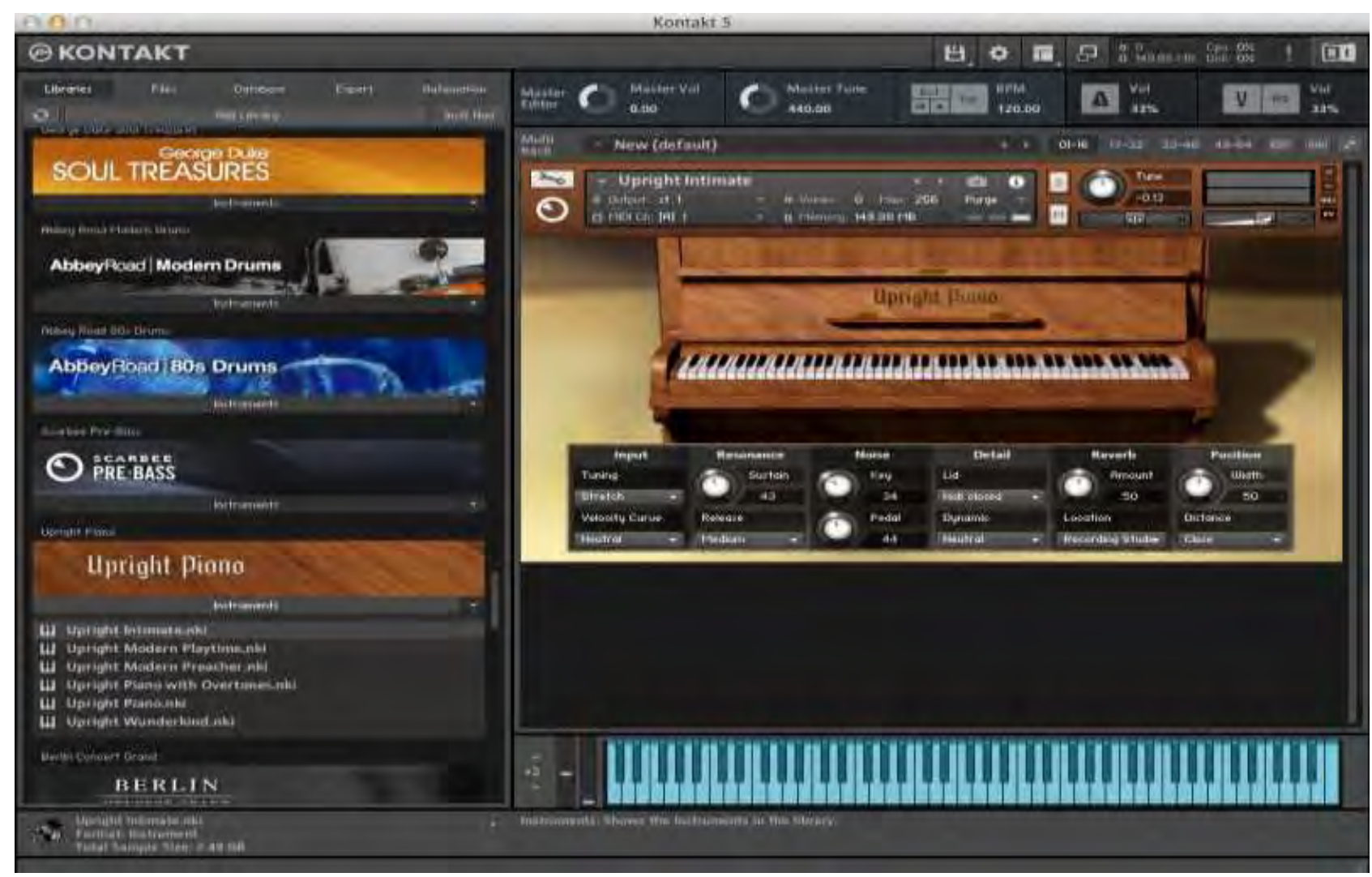

Fig. 5. Kontakt interface.

\section{To Train IT FROM Sight SingING AND EAR TRAINING}

The third point is the focus that the author wants to discuss. The author once talked with several colleagues about the most influential disciplines of traditional theoretical composition after dinner. The answer is "four major components", namely harmony, polyphony, musical form and orchestration. The author also proposed that the subject of Sight singing and ear training has a great influence on traditional theoretical composition. Imagine that if a composer's inner hearing is dull and his inner hearing is lacking in modality and tonality of "the generality writing period", even if he has excellent composing techniques, he cannot express the emotion he wants to express perfectly, let alone grasp the sound effect in his free atonal works. The cultivation of "set" thinking mode is more inseparable from the practice of sight singing and ear training. In sight singing, students should be able to quickly analyze and extract the specific pitch organization from the core motivation pitch material that appears repeatedly in works. 


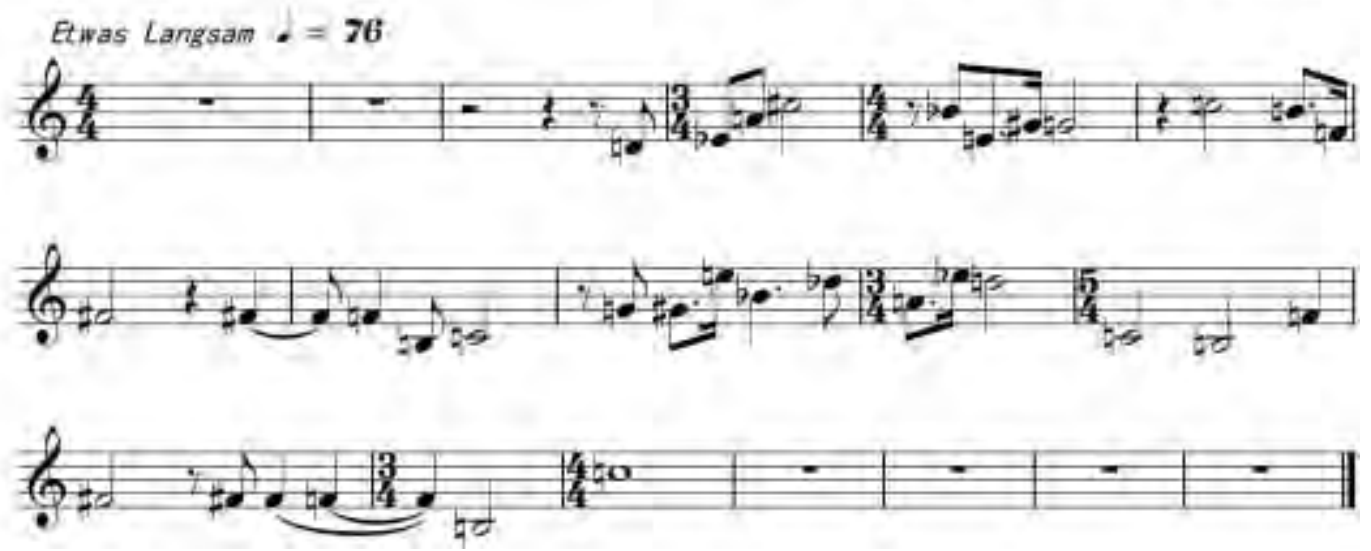

Fig. 6. Schoenberg's Three Artistic Songs op. 48 No. 2.

The sequence prototype used in the work:

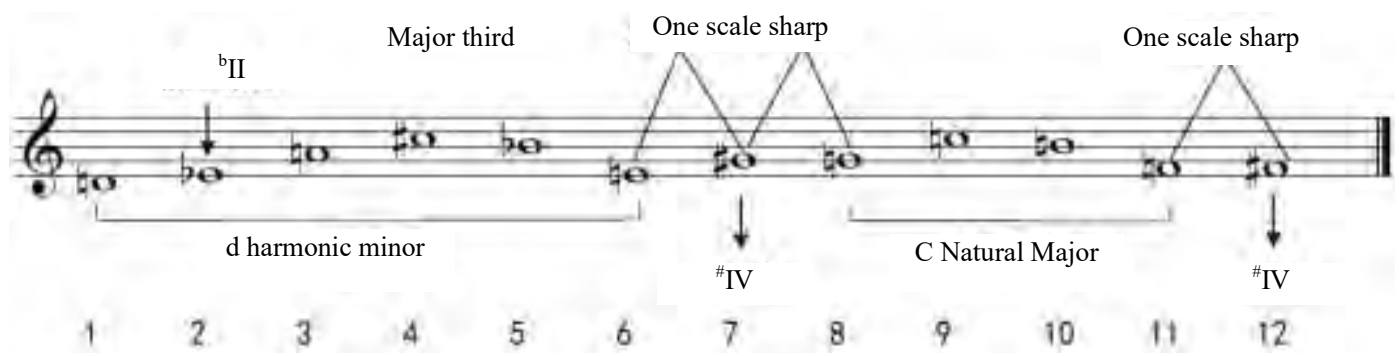

Fig. 7. Score 3: Schoenberg's Three Artistic Songs OP. 48 No. 2.

Score 3 is the second work of Schoenberg's Three Artistic Songs OP. 48 as in "Fig. 6" and "Fig. 7". The sequence prototype used in the work is shown in the figure. The first six tones of the sequence can be conceived as the mode sense of $\mathrm{d}$ harmony minor in sight singing, and the sense of interval that is continuously carried out should be noticed in sight singing, so as to grasp the direction of interval. The second tone in the fourth bar of the work can be conceived as the two-level falling tone in $\mathrm{d}$ harmony minor and the fourth tone as the characteristic tone of mode. However, the actual piano accompaniment of the second tone is the sound effect of nontraditional chords. Therefore, the two-level falling tone in $\mathrm{d}$ harmony minor is conceived only for the convenience of sight singing. In fact, the accompaniment of falling $\mathrm{E}$ does not have the harmony effect of Naples chords, as shown in "Fig. 8":

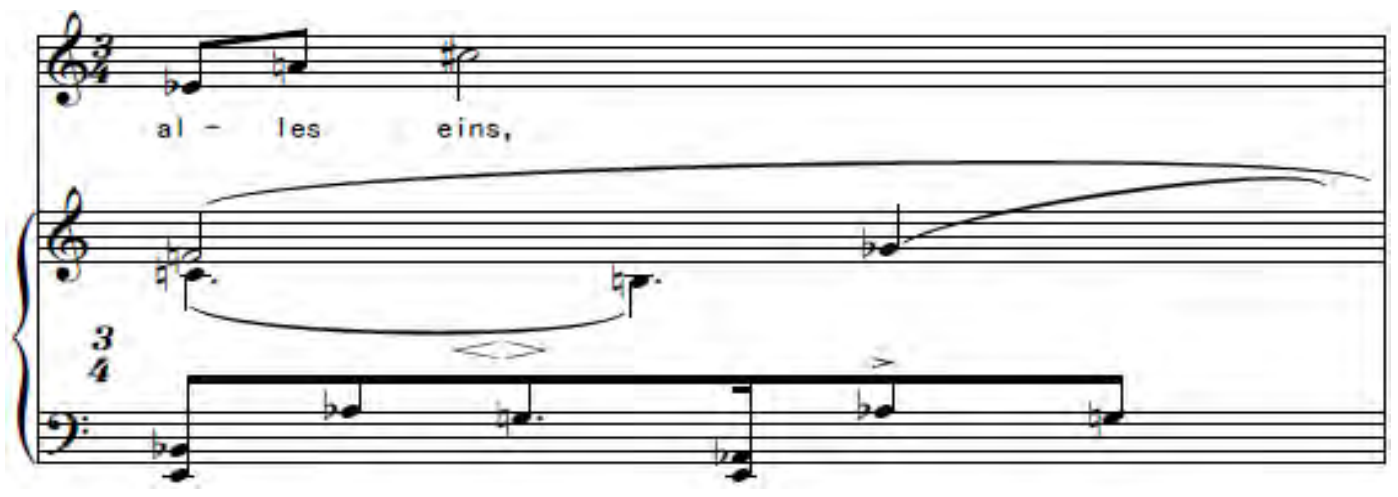

Fig. 8. Schoenberg's Three Artistic Songs op. 48 No. 2. (4bars).

The accompaniment part appears E-flat, but the accompaniment is the sound effect of non-traditional chords. Therefore, it should be noted that the sight singing and premonitory melody can be carried out by the way of "conceiving the sense of mode". But the adjustment of the pitch in detail must focus on the pitch position of the 
accompaniment part with the ear, and find the "harmony point" corresponding to the pitch. In short, the sight singing method of "conceiving the sense of mode" can quickly give a general sense of the melody of the work, and students can made it according to their proficiency in the sense of mode of tonal works. If it is only a sight singing of monophonic work, students can try to adjust the pitch in accordance with the conceived inner mode in singing. For the serial works of accompaniment sight singing form, if we want to make specific pitch accurate in sight singing, it is necessary to find the "harmony point" between the human pitch and the instrument pitch according to the actual pitch of the main piano or accompaniment instrument. The sixth, seventh and eighth tones in the sequence prototype can be fast sung according to the sense of interval. The seventh tone can also be conceived as the ascending fourth tone of d-harmonic minor. The progress of \#G to $G$ tone can even be conceived as the progress of d-harmonic minor from double dominant chords to dominant seventh chord. G tone needs to be solved according to the processing way of tonality works. But the $\mathrm{G}$ tone in the works goes directly to $\mathrm{C}$ tone. Therefore, starting with $\mathrm{G}$, it can be conceived as "the mode feeling" in C Natural Major to the 11th tone in the sequence, and the 11th and 12th tones give an interval feeling of minor second. The rising $\mathrm{F}$ tone at the end of the sequence can be conceived as a rising fourth tone in $\mathrm{C}$ Natural Major. In sight singing, we should accumulate the way of "set" thinking. When we guide students to analyze the core material used by composers, we should tell students how to use such pitch material in composition and create a sound effect different from the original work and express the content they want to express.

In the process of sight singing and ear training, teachers can even train students' "set" thinking in the listening, and guide students to accumulate sensibility, so as to eventually apply it to theoretical composition.

Webern's Three Artistic Songs op. 25 No. 1

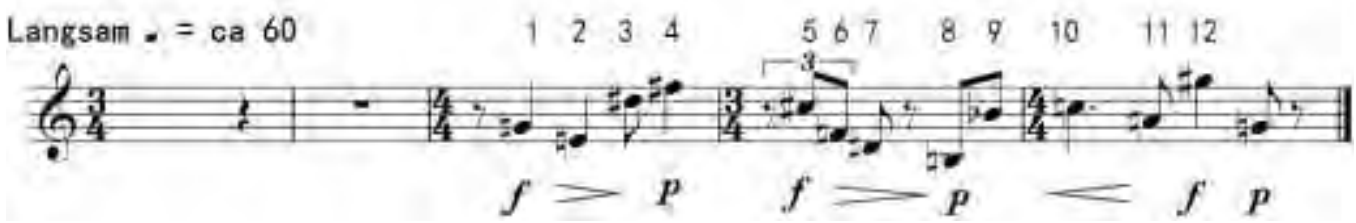

Fig. 9. Score 4: Webern's Three Artistic Songs OP. 25 No. 1.

Score 4 is an excerpt from Webern's Three Artistic Songs OP. 25 No. 1 (see "Fig. 9"). In the listening stage, the teacher does not need to write out the specific pitch, but writes down "the three-tone set" which is structurally characterized by a subset of truncated sequences. Use the "set" thinking mode to accumulate the core pitch material. Don't focus on specific phonetic names. Pay more attention to the direction of "the ordered pitch" between adjacent two tones in each set and the distance sense of "the disordered pitch interval" between the two intervals; pay attention to "the space imagination of the keyboard" when listening. Listen and write in accordance with "ordered pitch intervals", as shown in "Fig. 10".
Set 1:

Ordered pitch
interval:
Mark of tone
sequence:
Unordered scale
interval:

Interval vector:

Set prototype:

101100

Set 2:
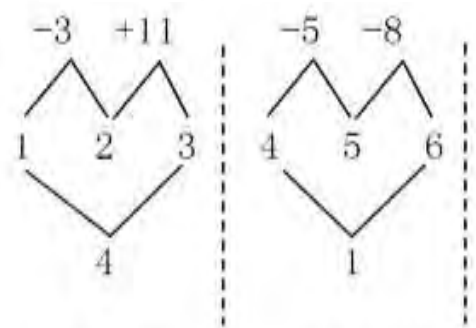

100110

101100

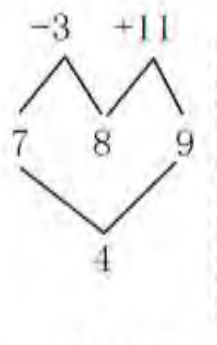

101100
Set 4:

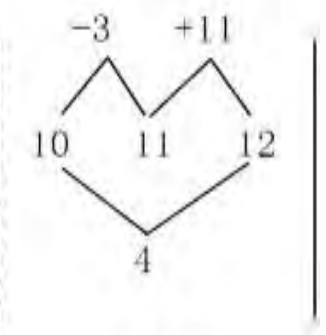

101100

$$
3-3(014) \quad 3-4(015) \quad 3-3(014) \quad 3-3(014)
$$

Fig. 10. Listen and write in accordance with "ordered pitch intervals".

Step 1: "The ordered pitch interval" of the first, second and third tones are written as "-ip3" and "+ ip11". "The disordered pitch interval" of the first and third tones is "i4". "Set 1" contains all disordered pitch intervals, including "i1", "i3" and "i4". The interval vector is 101100, in Set 3-3 (014).
Step 2: "The ordered pitch interval" of the 4th, 5th and 6th tones are written as "-ip5" and "ip8". "The disordered interval" of the 4th and 6th tones is "i1". "Set 2" contains all disordered intervals, including "i1", "i4" and "i5". The interval vector is 100110, in Set 3-5 (015). 
Step 3: "The ordered pitch intervals" of the 7th, 8th and 9th tones are written as "-ip3" and "+ip11". "The disordered pitch interval" of the 7th and 9th tones is "i4". "Set 3" contains all disordered pitch intervals, including "i1", "i3" and "i4". The interval vector is 101100, in Set 3-3 (014).

Step 4: "The ordered pitch intervals" of the 10th, 11th and 12th tones are written as "-ip3" and "+ip11". "The disordered interval" of the 10th and 12th tones is "i4". "Set 4" contains all disordered pitch intervals, including "i1", "i3" and "i4". The interval vector is 101100 , in Set 3-3 (014).

At the end of the interval listening and recording, the pitch relationship of the subset structure in the sequence can be analyzed. The sequence of this work is mainly composed of Set 3-3 (014) and Set 3-4 (015) as the main subset structure. At the same time, through the hearing of "ordered pitch interval" one can clear analyze the shape of mutual pitch structure shift in the process of specific pitch in Set 1, 3 and 4. In the course of Sight singing and ear training, teachers can help train students "set" thinking mode. After paying attention to the core pitch material of the works in sight singing or ear training, students should be guided to transform into their own combination mode and creative perception.

\section{CONCLUSION}

From three aspects, this paper discusses the training scheme of the "set" thinking mode proposed by the author. To sum up, as Mr. Chen Mingzhi said in the Preface 2 of Zhao Xiaosheng's Traditional Composition Techniques, "Tradition and modernity are not separated. Only by observing tradition with a modern perspective, can we use tradition for our own use and create new things in modern times." In this paper, the author puts forward that the training of students' "set" thinking mode in traditional composing teaching is the same reason. The difference between this mode of thinking and traditional composing mode is not big, but in the process of teaching, students need to change and quantify the sound effect of the core motivation material of each work they imitate, so as to achieve the effect of "there are a thousand Hamlets in a thousand people's eyes". It is true that every composer or student cannot be uniform in their own way of glowing and fever, and the same is true for teachers' teaching methods.

\section{REFERENCES}

[1] Kustka. Materials and Techniques of Music in the Twentieth Century. Beijing: People's Music Publishing House, 1st edition, 2002. (in Chinese)

[2] Yao Henglu. Course of Modern Music Analysis Methods, Hunan: Hunan Literature and Art Publishing House, 1st edition, 2003. (in Chinese)

[3] Qian Renkang and Qian Yiping. Course of Musical Works Analysis, Shanghai: Shanghai Music Publishing House, 1st edition, 2001. (in Chinese)

[4] Zheng Yinglie. The Basis of Serial Music Writing. Shanghai: Shanghai Music Publishing House, first edition, 1989. (in Chinese)

[5] Zheng Min. Modern Music Sight singing Course. Shanghai: Shanghai Conservatory of Music Press, first edition, 2004. (in Chinese)

[6] Zhao Xiaosheng. Traditional Composition Techniques. Anhui: Anhui Literature and Art Publishing House, 1st edition, 2003. (in Chinese)
[7] Alan Ford. The Structure of Atonal Music. Translated by Luo Zhongrong. Shanghai: Shanghai Music Publishing House, 1st edition, 2009. (in Chinese)

[8] Joseph N Strauss. Introduction to Post-tonality Theories. Translated by Gao Chang and Chang Qinke. Internal Materials of Sichuan Conservatory of Music, June 2012. (in Chinese)

[9] Roig Francoli. Understanding Post-tone Music. Translated by Du Xiaoshi and Tan Gesheng. Beijing: People's Music Publishing House, January 2012. (in Chinese)

[10] Wang Jing. Research on Interval-level Sight Singing of Modern Music, Wuhan Conservatory of Music, Master, 2007. (in Chinese)

[11] Yang Lu. Modern Music Sight singing Teaching Research, Xi'an Conservatory of Music, Master, 2010. (in Chinese)

[12] Chen Dacang. Cultivation of the Way of Thinking and Scientific Way of Thinking in Inner Hearing Practice, Music Exploration, No. 4, 2008. (in Chinese)

[13] Tang Junyan. Application of Set Theory in Sight Singing Teaching "Set" Hearing Training, Symphony, No. 4, 2012. (in Chinese)

[14] Tang Junyan. Training of "Tone Factor" in Sight Singing of Atonal Music in Sequence, Yuefu Xinsheng, No. 4, 2012. (in Chinese) 